\title{
COMMENTARY
}

\section{Prognostic value of pulmonary dead space in patients with the acute respiratory distress syndrome}

\author{
Michael A Matthay ${ }^{* 1}$ and Richard H Kallet ${ }^{2}$ \\ See related research by Charron et al., http://ccforum.com/content/15/4/R175/abstract
}

\begin{abstract}
A study published in the previous issue of Critical Care demonstrates that measurement of the pulmonary dead-space fraction is superior to hypoxemia as an indicator of a favorable physiologic response to prone positioning in patients with severe acute respiratory distress syndrome. These results add to the growing evidence supporting the clinical and research value of measuring pulmonary dead space in patients with acute respiratory distress syndrome and using this pulmonary physiologic end-point as one indicator of a favorable response to therapy.
\end{abstract}

In the previous issue of Critical Care, a new study reports that elevated pulmonary dead space is superior to measures of oxygenation (arterial partial pressure of oxygen/fraction of inspired oxygen, or $\mathrm{PaO}_{2} / \mathrm{FiO}_{2}$ ) for predicting physiologic and clinical responses to the prone position in patients with severe acute respiratory distress syndrome (ARDS) $\left(\mathrm{PaO}_{2} / \mathrm{FiO}_{2}\right.$ of less than $100 \mathrm{~mm} \mathrm{Hg}$ ) [1]. In addition, the authors found that a decrease in arterial partial pressure of carbon dioxide $\left(\mathrm{PaCO}_{2}\right)$ was superior to indices of oxygenation as a method for identifying responders to prone positioning. Also, the authors reported that a recently proposed method to estimate physiologic dead space did not have the same prognostic value as a direct measurement of physiologic dead space [2].

*Correspondence: michael.matthay@ucsf.edu

'Departments of Medicine and Anesthesiology and the Cardiovascular Research Institute at the University of California, San Francisco, 505 Parnassus Avenue, M-917, San Francisco, CA 94143-0624, USA

Full list of author information is available at the end of the article
For many years, arterial hypoxemia was considered to be the primary physiologic abnormality that characterized the gas-exchange impairment in critically ill patients with ARDS. As far back as 1975, the interrelationship between lung recruitment and oxygenation with improvements in both lung compliance and alveolar dead space was elegantly demonstrated by Suter and colleagues [3]. Yet only in the past decade has there been a growing recognition that abnormalities in alveolar ventilation and carbon dioxide $\left(\mathrm{CO}_{2}\right)$ excretion are equally important in contributing to the pulmonary physiologic abnormalities in patients with ARDS. A prospective study of 179 patients in whom pulmonary dead space was measured within 24 hours of ARDS onset indicated that dead space was markedly elevated in the early phase of ARDS and was associated with higher mortality [4]. Subsequent work has confirmed that an elevated pulmonary dead space frequently occurs in the early phase of ARDS and has prognostic value [5-8].

The results of the current study are important because they demonstrate the potential value of directly measuring pulmonary dead space as a physiologic endpoint in patients being treated with a new therapeutic modality (in this case, prone positioning). The value of measuring pulmonary dead space also was reported in a recent clinical trial of activated protein $C$ in patients with non-septic acute lung injury [9]. In addition, the current study found that changes in pulmonary dead space did not correlate well with indices of oxygenation and actually correlated better in an inverse relationship to quasi-static respiratory compliance. This result matches well with a prior study in which measurement of oxygenation by $\mathrm{PaO}_{2} / \mathrm{FiO}_{2}$ in patients with ARDS had less prognostic value for mortality than a direct measurement of the pulmonary dead space [4].

Traditionally, determining how effective prone positioning is and, in turn, whether this therapy should be continued has been judged by improvements in oxygenation [10]. However, prone positioning may 
improve mortality in the subset of patients with severe ARDS [11], so that using the most sensitive test for detecting a positive response assumes greater importance. ARDS is a heterogeneous disease containing lung compartments in which the time course for complete recruitment may take hours [12]. In the current study, maximal improvements in dead-space ventilation tended to occur earlier (3 hours) compared with maximal improvements in oxygenation (15 hours). Therefore, measuring dead space appears to be a particularly expedient way to assess the potential effectiveness of prone positioning. That improvement in pulmonary dead space is a more sensitive indicator of lung recruitment may reflect the fact that $\mathrm{CO}_{2}$ is much more diffusible across tissue membranes than oxygen [13], so that even small improvements in aeration from early recruitment of perfused alveoli are more likely to produce a detectable signal.

The current study also demonstrated that estimates of dead space using a recently proposed method [2] significantly underestimated actual measured pulmonary dead space. We are not surprised by this finding, because the gold standard for dead-space measurements requires that arterial blood gas sampling occur simultaneously with the mixed expired $\mathrm{CO}_{2}$ sampling. This standard was lacking in the validation study by Siddiki and colleagues [2]. We have found that, even over relatively brief periods of time, the mixed expired $\mathrm{CO}_{2}$ can fluctuate by 3 to $9 \mathrm{~mm} \mathrm{Hg}$, which could introduce a measurement error of between $10 \%$ and $20 \%$.

There are some limitations to the current study, most importantly the small number of patients $(n=13)$ who were included. Also, the study was focused only on patients with very severe ARDS $\left(\mathrm{PaO}_{2} / \mathrm{FiO}_{2}\right.$ of less than $100 \mathrm{~mm} \mathrm{Hg}$ ), although this is a group for whom rescue therapies and physiologic evaluations are important [14]. However, the results of the current study match well with a prior study in which a decline in $\mathrm{PaCO}_{2}$ was of greater prognostic value in prone-position therapy for acute lung injury than indices of oxygenation [15]. In conclusion, the current study adds to the growing evidence that supports the clinical and research value of measuring pulmonary dead space in patients with ARDS and using this pulmonary physiologic end-point as one indicator of response to therapy.

\section{Abbreviations}

ARDS, acute respiratory distress syndrome; $\mathrm{CO}_{2^{\prime}}$ carbon dioxide; $\mathrm{FiO}_{2^{\prime}}$ fraction of inspired oxygen; $\mathrm{PaCO}_{2^{\prime}}$ arterial partial pressure of carbon dioxide; $\mathrm{PaO}_{2^{\prime}}$, arterial partial pressure of oxygen.

\section{Competing interests}

The authors declare that they have no competing interests.

\section{Author details}

'Departments of Medicine and Anesthesiology and the Cardiovascular Research Institute at the University of California, San Francisco, 505 Parnassus Avenue, M-917, San Francisco, CA 94143-0624, USA. ${ }^{2}$ Respiratory Care Division, Department of Anesthesia, University of California, San Francisco at San Francisco General Hospital, 1001 Potrero Ave, San Francisco, CA 94110, USA.

Published: 25 October 2011

\section{References}

1. Charron C, Repesse X, Bouferrache K, Bodson L, Castro S, Page B, Jardin F Vieillard-Baron $\mathrm{A}$ : $\mathrm{PaCO} 2$ and alveolar dead space are more relevant than $\mathrm{PaO} 2 / \mathrm{FiO} 2$ in monitoring the respiratory response to prone position and acute inspiratory distress syndrome patients: a physiologic study. Crit Care 2011, 15:R175.

2. Siddiki H, Kojicic M, Li G, Yilmaz M, Thompson TB, Hubmayr RD, Gajic O: Bedside quantification of dead-space fraction using routine clinical data in patients with acute lung injury: secondary analysis of two prospective trials. Crit Care 2010, 14:R141.

3. Suter PM, Fairley HB, Isenberg MD: Optimum end-expiratory airway pressure in patients with acute pulmonary failure. N Engl J Med 1975, 292:284-289.

4. Nuckton TJ, Alonso JA, Kallet RH, Daniel BM, Pittet JF, Eisner MD, Matthay MA: Pulmonary dead-space fraction as a risk factor for death in the acute respiratory distress syndrome. N Engl J Med 2002, 346:1281-1286.

5. Cepkova M, Kapur V, Ren X, Quinn T, Zhuo H, Foster E, Liu KD, Matthay MA: Pulmonary dead space fraction and pulmonary artery systolic pressure as early predictors of clinical outcome in acute lung injury. Chest 2007, 132:836-842.

6. Kallet RH, Alonso JA, Pittet JF, Matthay MA: Prognostic value of the pulmonary dead-space fraction during the first 6 days of acute respiratory distress syndrome. Respir Care 2004, 49:1008-1014.

7. Gattinoni L, Carlesso E, Cressoni M: Assessing gas exchange in acute lung injury/acute respiratory distress syndrome: diagnostic techniques and prognostic relevance. Curr Opin Crit Care 2011, 17:18-23.

8. Raurich JM, Vilar M, Colomar A, Ibanez J, Ayestaran I, Perez-Barcena J, Llompart-Pou JA. Prognostic value of the pulmonary dead-space fraction during early and intermediate phases of acute respiratory distress syndrome. Respir Care 2010, 55:282-287.

9. Liu KD, Levitt J, Zhuo H, Kallet RH, Brady S, Steingrub J, Tidswell M, Siegel MD, Soto G, Peterson MW, Chesnutt MS, Phillips C, Weinacker A, Thompson BT, Eisner MD, Matthay MA: Randomized clinical trial of activated protein C for the treatment of acute lung injury. Am J Respir Crit Care Med 2008, 178:618-623.

10. Langer M, Mascheroni D, Marcolin R, Gattinoni L: The prone position in ARDS patients. Chest 1988, 94:103-107.

11. Gattinoni L, Tognoni G, Pesenti A, Taccone P, Mascheroni D, Labarta V, Malacrida R, Di Giulio P, Fumagalli R, Pelosi P, Brazzi L, Latini R; Prone-Supine Study Group: Effect of prone positioning on the survival of patients with acute respiratory failure. N Engl J Med 2001, 345:568-573.

12. Kallet RH, Katz JA: Respiratory system mechanics in acute respiratory distress syndrome. Respir Care Clin 2003, 9:297-319.

13. West JB: Respiratory Physiology: The Essentials. 8th edition. Philadelphia: Lippencott Williams \& Williams; 2008:26.

14. Diaz JV, Brower R, Calfee CS, Matthay MA: Therapeutic strategies for severe acute lung injury. Crit Care Med 2010, 38:1644-1650.

15. Gattinoni L, Vagginelli F, Carlesso E, Taccone P, Conte V, Chiumello D, Valenza F, Caironi P, Pesenti A: Decrease in $\mathrm{PaCO} 2$ with prone position is predictive of improved outcome in acute respiratory distress syndrome. Crit Care Med 2003, 31:2727-2733.

doi: $10.1186 /$ cc10346

Cite this article as: Matthay MA, Kallet RH: Prognostic value of pulmonary dead space in patients with the acute respiratory distress syndrome. Critical care 2011, 15:185. 